\title{
GENDER, AGE AND RELIGION AS \\ DETERMINANTS OF EATING HABIT OF YOUTH IN IKENNE LOCAL GOVERNMENT OF OGUN STATE, NIGERIA.
}

\author{
ADEOYE, O. Ayodele \\ Department of General Studies, School of Education and Humanities \\ Babcock University, Ilishan - Remo, Nigeria \\ evangadeoye2002@yahoo.com
}

Tel: 08038608585

and

ADEOYE, Bolade, K.

Food Services Department, Babcock University

Ilishan-Remo, Nigeria

evangadeoye2002@gmail.com

\begin{abstract}
The study examined the influence of Age, Gender and Religion on eating habit of youth. It made use of simple random technique in selecting 400 youths within Ikenne local government of Ogun State, Nigeria. The age range of the respondents was between 15 years and 40 years with the mean age of 25.2 and standard deviation of 3.291. The ex-post facto research design was employed. A 20 item questions by Snell EJohnson (1997) named psychology of eating questionnaire (PEQ) was adopted with four subscales and used in generating data for the study. Data analysis involved the use of analysis of variance, and independent $t$-test. The results indicated that the three variables age, gender and religion taken together accounted for $30.2 \%$ of the variance in eating habit pattern and were found to the significant with $\left\{F_{3.397}\right\}=5.214$. On the basis of this finding, it is then suggested that: Eating habit is affected by gender and age, nutritionist, social workers and those concerned with health should create more awareness on the poor eating habit as regards to healthy living.
\end{abstract}

Key words: Gender, Age, Religion, and eating habit

\section{Introduction}

The causes and effects of unhealthy eating habit in our society have been recognized for quite some time. Food and nutrition are critically involved in the development and clinical expression of illnesses, including 
cardiovascular diseases, cancers, obesity and type 2 diabetes, which today are the most widespread diseases in Nigeria and all industrialized and developing countries.( Pollitt \& Mathews, 1998; Squires,2001). The mounting physical, mental, and financial problems are leading doctors and researchers alike to try to determine what can be done to reverse this trend of unhealthy eating habit in our country. It is recognized that those who develop healthy eating habits early in life are likely to maintain them into adulthood, and have a reduced risk of chronic diseases (World Health Organization, 2003). Thus a balanced and appropriate diet during childhood and adolescence is likely to reduce the risk of diseases.

Patterns of eating had been observed to be important for healthy living; those who skip breakfast are most likely to have difficulty in concentrating by mid-morning and are more likely to consume snacks high in fat, salt and sugar at other times during the day. (Resnicow, 1991). In a research conducted in some selected countries in Europe, those who had breakfast every morning on school days were on the average, $69 \%$ for boys and $60 \%$ for girls. Major geographic differences were found in relation to eating breakfast, and gender differences became more pronounced with age. Breakfast consumption fell to $9 \%$ among boys and $17 \%$ among girls between the ages of 11-15 years. The decrease with age was most evident in girls in the Netherlands, with a $29 \%$ decrease. (Harnack, Stang \& Story ,1999). World health organization (2003), reported that $32 \%$ of boys and $25 \%$ of girls drank sugared drinks daily. Daily consumption of sugared soft drinks was as high as $40 \%$ in Israel, Malta, the Netherlands, Slovenia, Scotland (United Kingdom) and the United States. Consumption was lowest for all age groups in the Scandinavian countries (except Norway), the Baltic states, Greece and Ukraine, where less than $20 \%$ reported taking soft drinks daily. More boys than girls drank soft drinks every day in most countries and regions and across all age groups(World Health Organization, 2004). Almost one third of 11, 13 and 15 year-olds ate sweets or chocolates once or more every day, and a similar proportion (29\%) consumed such foods once a week or less. Young people reported eating sweets less frequently in Denmark, Finland, Norway, and Sweden. Malta had the highest percentage of daily consumers (54\%), followed by Scotland (United Kingdom) and Ireland (45\% and $49 \%$, respectively). Overall, age and gender differences in the consumption of sweets and chocolate were minor compared to those that applied to the other food and drink items surveyed. The total proportion of young people who ate fruit five days or more during the week was $45 \%$ for boys and $51 \%$ for girls, with responses ranging from $30 \%$ to $67 \%$. More girls reported eating fruit every day in 
nearly all countries and regions, but there was considerable geographic variation. Less than $50 \%$ of all young people reported eating vegetables daily. Again, girls in general reported eating vegetables more often than boys, $34 \%$ and $28 \%$ respectively. (World Health Organization, 2004)

Research has also linked unhealthy eating habit to lower selfesteem, negative self-image and higher rates of psychosocial difficulties experienced by adolescent (Mellin, 2002; Dietz, 1998; Squires, 1998). Another research has suggested that there may be an association between poor academic performance and eating habit (Johnson, 1996).

Vereecken (2005) revealed that fruit consumption increased with family's material wealth and higher parental occupational status The same study showed that pupils of parents within higher occupational status reported lower soft drink consumption in northern, southern and western European countries, but not in central and eastern European countries, where a significant increase in soft drink consumption with increasing family affluence was found(Janssen, 2004). According to Schlosser (2001) and Young (2005), unhealthy eating habits and sedentary lifestyles are closely bound not only to various socioeconomic indicators such as the parents' education levels, financial resources and professional situations, but also to living in economically deprived areas. The links between dietary habits and socioeconomic determinants for adults are well-documented. The consumption of fruits, vegetables and fish is lower in populations of low socioeconomic status, while the consumption of fats and soft drinks is greater than in populations with higher socioeconomic status. Also, a clear socio- economic gradient was observed for fruits and vegetable with children and adolescent from higher socio -economic groups eating more than these from lower groups (World Health Organization, 2004). A clear socio-economic pattern exists in the area of healthy eating and young people. Those from higher socio-economic backgrounds are more likely to have less- healthy diets with more fat and sugar content (Inchely, 2001).

In the eating habit behaviour carried out by Nigerian schools between 1985 and 2001, the trend showed that intake of fruits and vegetable decreased while intake of sweet and soft drinks increased within the same period. Age was regarded as a strong indictor of the negative development of eating habits. In 2001, the data showed that fruits and vegetable consumption decreases between the age of 11 and 15 and intake of sweet and soft drinks increases. Statistics revealed that boys eat less fruits and vegetable than girls and consume more soft drinks (World Health Organization, 2004). 
It is obvious that most of the literatures cited are from the developing countries, that is, not much has been done in under developing and developing countries like Nigeria. In view of this, there is an obvious need to establish whether these variables taken together are good predictors of eating habit. And if they are which of these variables would best predict the eating habit of the youth. The focus of this present study therefore is to empirically determine weather gender, age and religion will collectively and individually determine the pattern of youth eating habit. It was hypothesized that:

1. There is no significant contribution of gender, age and religious believes on youth eating habit patterns.

2. There is no significant contribution of each at the independent variables (age, gender and religion) on dependent variable (eating habit)

3. There is no relationship between Gender, Age, Religion and eating habit.

\section{Method}

\section{Design}

The study adopted a descriptive survey design of ex-post facto type. This is so because the researchers are only interested in determining the influence of the predictor variables on the criterion variables.

\section{Sampling techniques}

The population for this study comprises of youth with age range from 15 - 40 years, chosen from Ikenne local government in Ogun State. A sample of 400 youths comprises of male and female was randomly selected. Each of the participants in the sample is either a Muslim or a Christian. The mean age of the respondent was 25.2 while the standard deviation was 3.291 .

\section{Instruments}

A questionnaire was utilized for data collection. The questionnaire titled Psychology of eating (PEQ) by Snell\& Johnson (1997) was adopted for the study. The PEQ contain 20 items which subjects respond to on a 5 point likert response rating scale which include: not all characteristics of me (5 points), slightly characteristic of me (4 points), some what characteristic of me (3 points), moderately characteristic of me ( 2 points)and very characteristic of me (1 point). The questionnaires consist of two sections, that is section A and B. Section A contains demographic information about the respondents such as Age, gender, religion, Number of meals in a 
day, education level, section B consists of structured questions in four subscales with five questions each. The author reported the scale has internal consistency with Chronbach's alpha reliability coefficient (r) of 0.94. The Researchers subjected the questionnaire to three weeks of pre and post test at 3 weeks interval. A co-efficient of 0.83 was recorded.

\section{Procedure:}

The questionnaires were administered personally by the researchers. It was made clear to them on the instrument that their response would be treated with utmost confidentiality and the exercise was for research purpose.

\section{Data Analysis}

The data collected were analyzed using Multiple regressions and Pearson correlation. The hypotheses were tested at 0.05 level of significance and the results are presented below.

\section{RESULTS}

$\mathrm{Ho}_{1:}$ - There is no significant contribution of gender, age and religious beliefs on youth eating habit patterns.

Table 1: Multiple regression table of independent variable on Gender, age grouping and religious belief on eating habit.

$\mathrm{R}=.556$
$\mathrm{R}^{2}=0.311364$

Adjusted $\mathrm{R}^{2}=0.302$

Standard error of estimate $=7.81414$

ANOVA $^{b}$

\begin{tabular}{|c|c|c|c|c|c|}
\hline Model & Sum of square & $\mathrm{df}$ & Mean Square & $\mathrm{F}$ & Significant \\
\hline Regression & 3248.656 & 3 & 1082.885 & \multirow{3}{*}{5.214} & \multirow{3}{*}{$.005^{a}$} \\
\hline Residual & 82452.136 & 397 & \multirow[t]{2}{*}{207.688} & & \\
\hline Total & 85700.792 & 400 & & & \\
\hline
\end{tabular}

(a) Predictors: \{constant\} religion, age, gender

(b) Dependent variable: eating habit

Result indicated that age, gender and religion taken together account for $30.2 \%$ of the variable in eating habit pattern. $\left\{R^{2}=.302\right\}$. However, this percentage is not so high and significant. This is reflected 
in F-ratio $\mathrm{F}$ at $\left\{\mathrm{F}_{3.397}\right\}=5.214$ which implies that these three independent variables are important predictors of eating habit pattern.

$\mathrm{Ho}_{2}$ : - There is no significant contribution of each of the independent variables (age, gender and religion) on dependent variable (eating habit)

Table 2: Summary of individual contribution of the predictors and criterion variable.

\begin{tabular}{|l|l|l|l|l|l|l|}
\hline \multirow{2}{*}{ Model } & $\begin{array}{c}\text { Unstandardized } \\
\text { Co-efficient }\end{array}$ & $\begin{array}{c}\text { Standardized } \\
\text { Co-efficient }\end{array}$ & \multirow{2}{*}{$\mathrm{t}$} & Significant & Remark \\
\cline { 2 - 7 } & $\beta$ & $\begin{array}{c}\text { Std. } \\
\text { Error }\end{array}$ & $\beta$ & & & \\
\hline Age & 1.611 & .0681 & 0.812 & 2.682 & .009 &. \\
\hline Gender & 2.321 & .0812 & 0.763 & 2.051 & .016 & $*$ \\
\hline Religion & .453 & .0883 & 0.175 & 1.892 & .171 & * \\
\hline \multicolumn{7}{|c|}{ *Significant $\{\mathrm{p}<0.05\}$} \\
\end{tabular}

Data analysis revealed that the three independent variables on eating habit pattern are significant except religion. Therefore Age, Gender and Religion contribute significantly to eating habit pattern. However, Age contributed most with a t-value of 2.682; followed by Gender with t-value of 2.051 and lastly by Religion with $\mathrm{t}$-value of 1.892 .

$\mathrm{Ho}_{3}$ :- There is no relationship between Gender, Age and Religion on eating habit.

Table 3 Correction Matrix of the Independent variable and dependent variable.

\begin{tabular}{|l|l|l|l|l|}
\hline Variables & Gender & Age & Religion & Eating habit \\
\hline $\begin{array}{l}\text { Gender } \\
\text { Pearson correlation }\end{array}$ & $\overline{218^{*}}$ & $.218^{*}$ & .136 & $318^{*}$ \\
\hline $\begin{array}{l}\text { Age } \\
\text { Pearson correlation }\end{array}$ & .136 & .118 & .118 & $.302^{*}$ \\
\hline $\begin{array}{l}\text { Religion } \\
\text { Pearson correlation }\end{array}$ & $.318^{*}$ & $.302^{*}$ & .086 & .086 \\
\hline $\begin{array}{l}\text { Eating Habit } \\
\text { Pearson correlation }\end{array}$ & & $\overline{0}$ & \\
\hline
\end{tabular}

${ }^{*}$ Correlation is significant at the 0.05 level

Result indicated that eating habit pattern is positively correlated to Gender $(\mathrm{r}=.318 ; \mathrm{p}<.05)$; Age $(\{\mathrm{r}=.302 ; \mathrm{p}<.05)$; and but not with 
religion $(\mathrm{r}=.086 ; \mathrm{p}>$.05) Gender also correlated with age $(\mathrm{r}=.218 ; \mathrm{p}<$. $05)$ but not with religion $(\mathrm{r}=.136 ; \mathrm{p}<.05)$; religion does not have a correlation with age $(\mathrm{r}=.118 ; \mathrm{p}>$.05).

\section{Discussion:}

The first hypothesis which states that there is no significant contribution of gender, age and religion belief on youth eating habits was rejected. This means that there are significant contributions of gender, age and religion belief to the eating habit.

The findings revealed that a combination of gender, age and religious belief when taken together could be effective in determining eating habit. The results showed that $30.2 \%$ of the variance in the eating habit pattern was accounted for by the three predictor variables. Although, the relationship between the criterion and predictor variables taken together was not too high as shown by the coefficient of multiple correlation $[R=.556]$, but the observed F-ratio of 5.214, significant at .05 level is an evidence that the effectiveness of a combination of the independent variables in the prediction of the eating habit pattern could not have happened by chance; notwithstanding that a large percentage could not be explained by current data. The results agree with research finding reported by (Kittler, Pamela G., \& Sucher, Kathryn P. 1998; Schlosser, 2001 and Holstein, 2003) that gender, and ages are good determinant of eating habit pattern.

The results obtained in table 2 run contrary to the expectation of the Researchers in that religious belief was expected to have a greater impact on eating habit, this is because religious tenets are to preach good habit and moral values, but we are proved wrong. The result revealed the contribution of the independent variables and the criterion. Two out of the predictor variables [Gender and Age] were found to contribute relatively to the prediction or determinant of eating habit. However, age grouping was found to be the best predictor of eating habit as its t-value is .2.682, followed by the gender with $\mathrm{t}$-value of 2.051 and by religious belief which seems to have no effect on eating habit pattern.

Table 3 shows the relationship between the variables. It was shown that there is a relationship between gender, age and eating habit and no relationship exist between the religious belief and the other variables. This implies that religion is a bad determinant of eating habit and has nothing to with age or gender. 


\section{Conclusion:}

From the finding of this study it is crystal clear that the issue of eating habit transcends just the age grouping and gender and religions. Although, they are determinants, but the higher percentage of the variance cannot be determined by the data. Understanding the sex and age range of individual with bad eating habit will help the psychologist, and nutritionist and others to assist youth who are having problems with eating habit.

\section{Recommendations:}

Given the significance of the finding of this study, the following are recommended:

1. Schools should re-introduce health education into their syllabus and teach the young ones good eating habit. Thus a partnership can be formed between ministry of education and ministry of health.

2. The nutrition expert, psychologist and others who are concerned with youth welfare should mount a campaign and create awareness on the need to maintain good eating habits.

3. Families should also play a role in cultivating and teaching good eating habits for the younger ones.

\section{References}

Campbell, K. (2002) Interventions for preventing obesity in children (Cochrane review). The Cochrane Library,

Dietz, K. (1998). Health consequences of obesity in youth: childhood predictors of adult disease. Paediatrics, 101(3 Pt 2), 518-25.

Holstein B. (2002) Socio-economic inequality and health. In: Currie C et al., eds. Young people's health in context. Health Behaviour in Schoolaged Children(HBSC) study: international report from the 2001/2002 survey. Copenhagen, WHO Regional Office for Europe

Harnack, L. Stang J. \& Story, M. (1999) Soft drink consumption among US children and adolescents: nutritional consequences. Journal of the American Dietetic Association, 99:436-441

Inchely, J. (2001). Dietary trends among Scottish schoolchildren in the 1990s. Journal of Human Nutrition and Dietetics. 14:207

Janssen, I. (2004). Overweight and obesity in Canadian adolescents and their associations with dietary habits and physical activity patterns Journal of Adolescent Health, 35:5:360-367

Kittler, Pamela G., Sucher, R. \& Kathryn P. (1998). Food and Culture in America: A Nutrition Handbook, 2nd edition. Belmont, CA: West/Wadsworth.hely, 2001) Adolescent Health, 35:5:360-367. 
Mellin , Y.(2002) Unhealthy behaviours and psychosocial difficulties among overweight adolescents: The potential impact of familial factors. Journal of Adolescent Health, 31, 145-53.

Pollitt, E. \& Mathews, R. (1998). Breakfast and cognition: an integrative summary. American Journal of Clinical Nutrition. 67: 804S-813S.

Resnicow, K. (1991). The relationship between breakfast habits and plasma cholesterol levels in schoolchildren. Journal of School Health. 61:81-85

Schlosser, E. (2001). Fast Food Nation: The Darker Side of the All American Meal. New York: Houghton Mifflin

Snell,W. \& Johnson, R. (1997) Multidimensional psychology of eating (MPEQ) SE Missouri State University Department of Psychology, wesnell@semovm.semo.edu

Squires, (1998). Health-related quality of life predicts survival, cytomegalovirus disease, and study retention in clinical trial participants with advanced HIV disease. Journal of Clinical Epidemiology, 2003, 56:874-879.

Vereecken, C.A (2005). The relative influence of individual and contextual socio-economic status on consumption of fruit and soft drinks among adolescents in Europe. European Journal of Public Health, 15:3:224-232.

World Health Organization (2003). Diet, nutrition and the prevention of chronic diseases. Report of a Joint World Health Organization/Food and Agriculture Organization of the United Retrieved from www.who.org on 27th January 2009..

World Health Organization, (2004). The global strategy on diet, physical activity and health. Geneva, Retrieved from www.who.org on 27th January 2009..

Williams, C. (1995) Healthy eating: clarifying advice about fruit and vegetables. British Medical Journal, 310:1453-1455.

Wills, W. Gregory S. \& Lawton, J. (2005) The influence of secondary schools on the food practices of young teenagers from disadvantaged backgrounds in Scotland. Health Education Research: Theory and Practice, , 20:4:458-465.

Young,I (2005) Health promotion in schools: a historical perspective. Health Promotion and Education, 2005, xii: 3-4. Special edition on school health promotion, International Union for Health Promotion and Education, Paris. 